Bangladesh J. Bot. 49(2): 343-348, 2020 (June)

\title{
OPTIMIZATION OF MYCOBIOSYNTHESIS OF SILVER NANOPARTICLES BY USING FUSARIUM 4F1 AND TRICHODERMA TRS ISOLATES
}

\author{
Shital Pal and KS Hossain* \\ Department of Botany, Jagannath University, Dhaka-1100, Bangladesh \\ Keywords: Mycobiosynthesis, Silver nanoparticles, Fusarium, Trichoderma
}

\begin{abstract}
Silver nanoparticles (Ag-NPs) by mixing silver nitrate $\left(\mathrm{AgNO}_{3}\right)$ with cell-free filtrate $(\mathrm{CFF})$ of the two fungal isolates viz., Fusarium $4 \mathrm{~F} 1$ and Trichoderma $\mathrm{TrS}$ were synthesized. $\mathrm{pH}$, substrate concentration and incubation period for the production of better quality and quantity of Ag-NPs was optimized. The Ag-NPs by UV-vis spectroscopy were characterized. Between the two fungal isolates, $\mathrm{pH}$ levels, $\mathrm{AgNO}_{3}$ concentrations and incubation periods studied, the highest number of spherical shaped, monodispersed and stable Ag-NPs were recorded from Fusarium $4 \mathrm{~F} 1$ at $\mathrm{pH} \mathrm{9,2} \mathrm{mM} \mathrm{AgNO}_{3}$ and $72 \mathrm{hrs}$ of incubation.
\end{abstract}

\section{Introduction}

Nanoparticles (NPs) are regarded as highly reactive elements because of the large surface area. They have novel magnetic, electronic and optical properties, which vary on the basis of their size, shape, and composition (Patil 2014). At present, different types of metal NPs are being produced. They have a wide range of applications in areas such as health care, biomedical sciences, cosmetics, drug-gene delivery, bactericidal, biological labeling, treatment of some cancers, optics, chemical industries, electronics, space industries, single electron transistors, light emitters, sensor technology, etc. (Iravani et al. 2014).

Numerous protocols have been developed to synthesize NPs following chemical, physical and biological methods (Rai et al. 2009). Among them, biological methods are considered as ecofriendly, high yielding, reliable, clean, and nontoxic (Gupta et al. 2012, Iravani et al. 2014, Patil 2014). Biosynthesis would have greater commercial acceptance if the NPs could be synthesized more rapidly and economically on a large scale. However, in order to achieve better control of size, morphology, stability, and NP production rate, biological methods could be used with some optimization (Korbekandi et al. 2013).

Microbes have been explored as a potential bio-factory for the synthesis of different metallic NPs (Korbekandi et al. 2013). Among different microbes some fungal isolates are capable of the NPs formation. The fabrication of NPs by fungi is an exciting modern field of applied interdisciplinary science. Because fungi have considerable potential in biosynthesis of NPs owing to their wide range and diversity (Rai et al. 2009).

Among different metal NPs, silver nanoparticles (Ag-NPs) have attracted increasing interest due to their unique physical, chemical and biological properties compared to their macro-scaled counterparts. Ag-NPs play a significant role in the field of biology and medicine (Patil 2014). AgNPs can be incorporated into antimicrobial applications, biosensor materials, composite fibers, cryogenic superconducting materials, cosmetic products, water purification systems, and electronic components. A combination of antibiotics and metal Ag-NPs could increase the antibiotics' efficacy against resistant pathogens (Fayaz et al. 2010, Sheng and Liu 2011).

*Author for correspondence: <ksh1968@gmail.com>. 
Mycobiosynthesis of Ag-NPs has not been reported so far in Bangladesh. The aim of the present work was to synthesize Ag-NPs in laboratory scale by Bangladeshi fungal isolates obtained from soil and optimized $\mathrm{pH}$ level, substrate concentration and incubation period for the production of higher quality and quantity of Ag-NPs.

\section{Materials and Methods}

Soil samples were collected from the pine plantation of the National Botanical Garden, Mirpur, Dhaka, Bangladesh. Fungi were isolated in pure culture following serial dilution and pour plate method using potato dextrose agar (PDA) medium supplemented with $0.1 \mathrm{mg} / \mathrm{ml}$ streptomycin sulfate to exclude soil bacteria (Aneja 2003). The fungal isolates were identified following standard literatures on the basis of their morphological characteristics (Booth 1971, Bissett 1991). Among the isolated fungi, Fusarium 4F1 and Trichoderma $\mathrm{TrS}$ were selected for the biosynthesis of Ag-NPs because the genera are reported to be promising Ag-NPs producer (Vahabi et al. 2011, Birla et al. 2013, Korbekandi et al. 2013).

To prepare biomass, Fusarium 4F1 and Trichoderma $\operatorname{TrS}$ were grown aerobically in potato sucrose and potato dextrose broth media ( $\mathrm{pH} 7$ ), respectively at $24 \pm 2^{\circ} \mathrm{C}$. The culture broth in the flasks were agitated at $170 \mathrm{rpm}$ on a rotary shaker for $72 \mathrm{hrs}$. The biomass was harvested after incubation using a plastic sieve. After that, it was thoroughly washed with sterile distilled water to remove any other component from the biomass.

To prepare Cell-Free Filtrate (CFF), approximately $20 \mathrm{~g}$ of fresh and clean biomass were taken in a $500 \mathrm{ml}$ Erlenmeyer flask containing $150 \mathrm{ml}$ of sterilized deionized water. The flask was incubated at $24 \pm 2^{\circ} \mathrm{C}$ on a rotary shaker for $72 \mathrm{hrs}$ and agitated at $170 \mathrm{rpm}$. After the incubation period, CFF was obtained by passing it through sterile Whatman filter paper No. 1.

For the biosynthesis of Ag-NPs, the silver nitrate $\left(\mathrm{AgNO}_{3}\right)$ solution was mixed with $c a .50 \mathrm{ml}$ fresh CFF of Fusarium 4F1 and Trichoderma $\mathrm{TrS}$ in several sets in $250 \mathrm{ml}$ Erlenmeyer flasks. The final concentration of the substrate $\left(\mathrm{AgNO}_{3}\right)$ in the solutions was $1 \mathrm{mM}$ and $\mathrm{pH}$ was adjusted to 7 , 8, and 9 separately. The flasks containing CFF without $\mathrm{AgNO}_{3}$ at $\mathrm{pH} 7,8$ and 9 were also maintained along with the treatment sets. These flasks were marked as control. Depending on the effects of $\mathrm{pH}$ on the quality and quantity of $\mathrm{Ag}$-NPs, separate sets of experiments were run where final concentration of the $\mathrm{AgNO}_{3}$ were $2 \mathrm{mM}$ and $\mathrm{pH}$ were 9 for both fungal isolates following the above mentioned procedure. In every sets, 3 replications were maintained. All flasks were fully covered with thick black paper and incubated on a rotary shaker and agitated at $170 \mathrm{rpm}$ at $24 \pm 2^{\circ} \mathrm{C}$ in dark.

Flasks were visually examined after every 24 hrs intervals up to 45 days to find any kind of change of $\mathrm{CFF}$ and $\mathrm{AgNO}_{3}$ mixture color. In every observation, data on color change were recorded and photographs of the flasks were also taken with a digital camera. Reaction mixture was withdrawn every after 24, 48 and $72 \mathrm{hrs}$ from each flask. UV-visible light absorption profile of the mixture was recorded to study the change in intensity of the brown color during incubation periods using a UV-Vis spectrophotometer (SPECORD 250 plus, Analytic Jena). The absorbance was measured from $300-600 \mathrm{~nm}$ at a resolution of $1 \mathrm{~nm}$. The control sets were used as reference in spectroscopy. It is generally recognized that UV-Vis spectroscopy could be used to examine the quality and quantity of NPs in aqueous suspensions (Wiley et al. 2006). The results were analyzed statistically for the test of significance using WASP 2.0 software. The experiments were conducted in the laboratory at the department of Botany, Jagannath University, Dhaka. 


\section{Results and Discussion}

The treatment flasks containing reaction mixture showed a change in color from almost colorless or light yellow to light brown or brown after 24,48 or $72 \mathrm{hrs}$ of incubation. The control sets did not show any change of color (Fig. 1). The appearance of the brown color was an indication of the formation of Ag-NPs in the reaction mixture. This observation was in agreement with the previous reports, where the brown color was considered as the production of colloidal suspension (hydrosol) of Ag-NPs (Ingle et al. 2008, Korbekandi et al. 2013). Metal NPs exhibited different colors in solution due to their optical properties. The appearance of brown color was owing to the excitation of free electrons in NPs. It gives the Surface Plasmon Resonance (SPR) absorption band by the combined vibration of electrons of metal NPs in resonance with light waves (Rai et al. 2009).

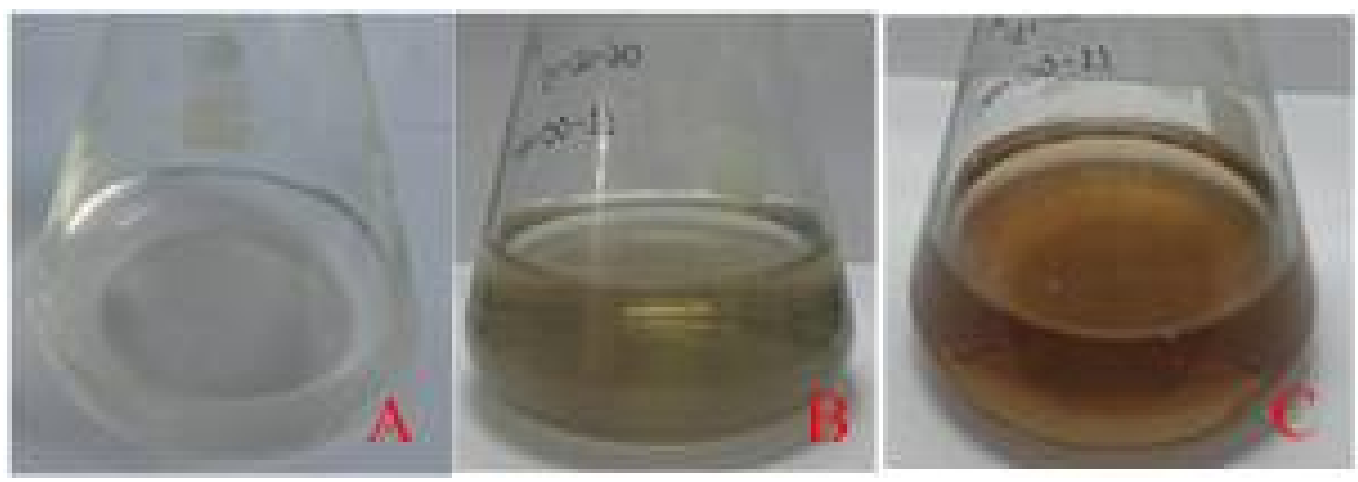

Fig. 1. Mycobiosynthesis of silver nanoparticles (Ag-NPs). A. Cell free filtrate (CFF) of Fusarium sp. B. CFF treated with $1 \mathrm{mM} \mathrm{AgNO}_{3}$ (final concentration) at $\mathrm{pH}$ 9. C. Color intensified at the treatment flask after 24 hrs incubation.

Ag-NPs are synthesized into the reaction mixture by the reduction of silver ions $\left(\mathrm{Ag}^{+}\right)$to metallic silver $\left(\mathrm{Ag}^{0}\right)$. The silver ions may require the NADH and NADH-dependent nitrate reductase enzyme for their reduction. Fungi may release proteins/enzymes into the extracellular $\mathrm{CCF}$. The reduction may occur due to the transfer of an electron from NADH where the NADHdependent reductase can act as an electron carrier. Consequently, the proteins also may bind to the NPs and enhance the stability (Duran et al. 2005).

At $\mathrm{pH} 7$ and 8, the color intensity of the reaction mixture gradually increased up to 9 - 10 days after incubation. It turned brown to deep blackish brown and remained constant after 45 days of observation for both the fungal isolates. A small amount of sedimentation also occurred at the reaction flasks (Table 1). The increase of color intensity could be owing to the gradual increasing of Ag-NPs and/or their aggregation. Sedimentation and turn of color into black/dark after a longstanding at $\mathrm{pH} 7$ and 8 was owing to much aggregation of Ag-NPs and/or conversion of Ag-NPs into silver oxide $\left(\mathrm{Ag}_{2} \mathrm{O}\right)$. The color of the aggregated Ag-NPs, became black because of its large size and losing of the property of SPR (Ingle et al. 2008, Rai et al. 2009).

At $\mathrm{pH} 9$, the color intensity and light absorbance increased up to $72 \mathrm{hrs}$ and remained constant after 45 days observation. There was no sedimentation in the reaction flask (Table 1 and Fig. 1). It might be due to the absence of aggregation of Ag-NPs in reaction mixture at $\mathrm{pH} 9$ for both the fungal isolates. It indicates that Ag-NPs were relatively stable at $\mathrm{pH}$ 9. It might be due to the adsorption of $\mathrm{OH}^{-}$on $\mathrm{Ag}-\mathrm{NPs}$, while at lower $\mathrm{pH}$ aggregates were formed due to the unavailability 
of $\mathrm{OH}^{-}$ions (Birla et al. 2013). Again high stability of NPs in the solution was found due to capping of the particles with certain proteins present in CFF which were released by the fungi. Stability of capping proteins depends on $\mathrm{pH}$. At higher $\mathrm{pH}$ values, the NPs in the solution remained stable, while they are aggregated at lower $\mathrm{pH}$ values as the protein was denatured (Kumar et al. 2007).

Table 1. UV-Vis spectroscopic properties of the reaction mixture containing CFF of Fusarium 4F1 and Trichoderma $\mathrm{TrS}$ at different $\mathrm{pH}$ levels, incubation periods and substrate concentrations.

\begin{tabular}{|c|c|c|c|c|c|c|c|}
\hline \multirow{3}{*}{$\begin{array}{c}\text { Fungal isolate name, } \\
\text { substrate conc. and } \\
\text { pH level }\end{array}$} & \multicolumn{6}{|c|}{ Incubation period } & \multirow{3}{*}{$\begin{array}{l}\text { Presence } \\
\text { of } \\
\text { sediment }\end{array}$} \\
\hline & \multicolumn{2}{|c|}{$24 \mathrm{hrs}$} & \multicolumn{2}{|c|}{$48 \mathrm{hrs}$} & \multicolumn{2}{|c|}{$72 \mathrm{hrs}$} & \\
\hline & $\begin{array}{l}\text { WAP } \\
(\mathrm{nm})^{*}\end{array}$ & $\begin{array}{c}\text { Absorbance } \\
\text { (a.u.) }\end{array}$ & $\begin{array}{l}\text { WAP } \\
(\mathrm{nm}) *\end{array}$ & $\begin{array}{c}\text { Absorbance } \\
\text { (a.u.) }\end{array}$ & $\begin{array}{l}\text { WAP } \\
(\mathrm{nm})^{*}\end{array}$ & $\begin{array}{c}\text { Absorbance } \\
\text { (a.u.) }\end{array}$ & \\
\hline \multicolumn{8}{|l|}{ Fusarium 4F1: } \\
\hline \multicolumn{8}{|c|}{ At $1 \mathrm{mM} \mathrm{AgNO}$ final concentration } \\
\hline pH 7 & 428 & $0.0195^{\mathrm{g}}$ & 436 & $0.0203^{\mathrm{h}}$ & 442 & $0.0211^{\mathrm{f}}$ & Scanty \\
\hline $\mathrm{pH} 8$ & 448 & $0.0211^{\mathrm{g}}$ & 457 & $0.0232^{\mathrm{g}}$ & 467 & $0.0261^{\mathrm{f}}$ & Scanty \\
\hline pH 9 & 440 & $0.3126^{\mathrm{a}}$ & 440 & $0.3345^{\mathrm{b}}$ & 440 & $0.3690^{\mathrm{b}}$ & No \\
\hline \multicolumn{8}{|c|}{ At $2 \mathrm{mM} \mathrm{AgNO} \mathrm{O}_{3}$ final concentration } \\
\hline pH 9 & 425 & $0.2905^{\mathrm{c}}$ & 425 & $0.3801^{\mathrm{a}}$ & 425 & $0.4556^{\mathrm{a}}$ & No \\
\hline \multicolumn{8}{|l|}{ Trichoderma TrS: } \\
\hline \multicolumn{8}{|c|}{ At $1 \mathrm{mM} \mathrm{AgNO} \mathrm{O}_{3}$ final concentration } \\
\hline pH 7 & 443 & $0.0841^{\mathrm{f}}$ & 442 & $0.1153^{f}$ & 441 & $0.1489^{\mathrm{e}}$ & Scanty \\
\hline pH 8 & 455 & $0.1183^{\mathrm{e}}$ & 456 & $0.1402^{\mathrm{e}}$ & 456 & $0.1616^{\mathrm{d}}$ & Scanty \\
\hline $\mathrm{pH} 9$ & 438 & $0.2831^{\mathrm{d}}$ & 439 & $0.2943^{\mathrm{d}}$ & 439 & $0.3306^{\mathrm{c}}$ & No \\
\hline \multicolumn{8}{|c|}{ At $2 \mathrm{mM} \mathrm{AgNO}$ final concentration } \\
\hline pH 9 & 428 & $0.3055^{\mathrm{b}}$ & 429 & $3267^{\mathrm{c}}$ & 429 & $3378^{\mathrm{c}}$ & No \\
\hline $\mathrm{CD}(0.01)$ & & 0.001 & & 0.006 & & 0.001 & \\
\hline $\mathrm{CD}(0.05)$ & & 0.004 & & 0.001 & & 0.008 & \\
\hline $\mathrm{CV}^{* *}$ & & 1.427 & & 0.322 & & 0.198 & \\
\hline
\end{tabular}

$* \mathrm{WAP}=$ Average wavelength of absorbance peak. $* *$ All treatments found significant at 1 and $5 \%$ level of significance. Same letter beside means of absorbance in a column represent insignificant difference among them at $5 \%$ level.

The UV-Vis spectra at absorbance maxima of the reaction mixture containing CFF of Fusarium 4F1 and $1 \mathrm{mM} \mathrm{AgNO}$ solution at $\mathrm{pH} \mathrm{7,8}$ and 9 for 24, 48 and $72 \mathrm{hrs}$ of incubation period are presented in the Table 1 . At $\mathrm{pH} 7$, a strong absorbance peak was exhibited at $428 \mathrm{~nm}$ wavelength after $24 \mathrm{hrs}$ of incubation and shifted to 436 and $442 \mathrm{~nm}$ with increasing absorbance value as the reaction proceeded up to 48 and $72 \mathrm{hrs}$ of incubation, respectively. The same trends were observed at $\mathrm{pH} 8$. Whereas at $\mathrm{pH} 9$ the spectrum was stable at $440 \mathrm{~nm}$ but the absorbance was increased gradually up to $72 \mathrm{hrs}$ of incubation periods. The spectra at absorbance maxima were stable at $425 \mathrm{~nm}$ for $2 \mathrm{mM} \mathrm{AgNO}_{3}$ solution and gradual increase of the absorbance was also recorded. The highest absorbance value ( 0.4556 a.u.) was recorded here after $72 \mathrm{hrs}$ of incubation. 
In the case of Trichoderma Trs isolate, little $( \pm 1)$ or no shifting of spectra was found in all the reaction mixture sets. Gradual increase of the absorbance was also recorded. The highest absorbance ( 0.3378 a.u.) was recorded at $429 \mathrm{~nm}, \mathrm{pH} 9$ and $2 \mathrm{mM} \mathrm{AgNO}_{3}$ solution.

Close relationship between the UV-Vis absorbance peak and size and shape of Ag-NPs was detected by former workers (Sosa et al. 2003). The shift of spectrum towards smaller or longer wavelengths depends upon the particle size, shape and state of aggregation (Park and Kim 2008). According to the Mie's theory, only a single SPR band is expected in the absorption spectra of spherical metal NPs. Spherical Ag-NPs showed specific absorbance peak around $420( \pm 10) \mathrm{nm}$ (Novak and Feldheim 2000). At the same UV-Vis spectrum, an increase of absorption indicates increased amount of Ag-NPs at colloidal suspension. The stable position of absorbance peak indicates that the NPs do not aggregate (Vahabi et al. 2011).

From this study, it may be inferred that $\mathrm{pH} 9,72 \mathrm{hrs}$ of incubation period and $2 \mathrm{mM}$ concentration of $\mathrm{AgNO}_{3}$ are optima for mycobiofabrication of spherical, monodispersed and stable Ag-NPs by both fungal isolates.

\section{Acknowledgement}

The first author (SP) is very much grateful to The Ministry of Science and Technology, Govt. of the People's Republic of Bangladesh for awarding of National Science and Technology (NST) fellowship.

\section{References}

Aneja KR 2003. Experiments in Microbiology, Plant Pathology and Biotechnology. 4th ed. New Age International, New Delhi, India. pp. 607.

Birla SS, Gaikwad SC, Gade AK and Rai MK 2013. Rapid synthesis of silver nanoparticles from Fusarium oxysporum by optimizing physicocultural conditions. Sci. World J. 2013: 1-12.

Bissett J 1991. A revision of the genus Trichoderma. III. Section Pachybasium. Canad. J. Bot. 69(11): 23732417.

Booth C 1971. The genus Fusarium. Commonwealth Mycological Institute, Kew, Surrey, England. pp. 237.

Duran N, Marcato PD, Alves OL, De Souza IH and Esposito E 2005. Mechanistic aspects of biosynthesis of silver nanoparticles by several Fusarium oxysporum strains. J. Nanotech. 3(8): 1-7.

Fayaz AM, Balaji K, Girilal M, Yadav R, Kalaichelvan PT and Venketesan R 2010. Biogenic synthesis of silver nanoparticles and their synergistic effect with antibiotics: a study against gram-positive and gramnegative bacteria. Nanomedi. 6(1): 103-109.

Gupta S, Sharma K and Sharma R 2012. Myconanotechnology and application of nanoparticles in biology. Recent Res. in Sci. and Tech. 4(8): 36-38.

Ingle A, Gade A, Pierrat S, Sonnichsen C and Rai M 2008. Mycosynthesis of silver nanoparticles using the fungus Fusarium acuminatum and its activity against some human pathogenic bacteria. Current Nanosci. 4: $141-144$.

Iravani S, Korbekandi H, Mirmohammadi SV and Zolfaghari B 2014. Synthesis of silver nanoparticles: chemical, physical and biological methods. Res. in Pharmaceutical Sci. 9(6): 385-406.

Korbekandi H, Ashari Z, IravaniS and Abbasi S 2013. Optimization of biological synthesis of silver nanoparticles using Fusarium oxysporum. Iranian J. Pharmaceutical Res. 12(3): 289-298.

Kumar AS, Abyaneh MK, Sulabha SWG, Ahmad A and Khan MI 2007. Nitrate reductase-mediated synthesis of silver nanoparticles from $\mathrm{AgNO}_{3}$. Biotechnol. Lett. 29(3): 439-455.

Novak JP and Feldheim DL 2000. Assembly of phenylacetylene-bridged gold and silver nanoparticle arrays. J. Am. Chem. Soc. 122(16): 3979-3980.

Park J and Kim Y 2008. Effect of shape of silver nanoplates on the enhancement of surface plasmon resonance (SPR) signals. J. Nanosci. Nanotech. 8: 1-4. 
Patil SR 2014. Antibacterial activity of silver nanoparticles synthesized from Fusarium semitectum. CIB Tech. J. Biotech. 3(1): 08-12.

Rai M, Yadav A, Bridge P and Gade A 2009. Myconanotechnology: a new and emerging science. In: Rai M. and Bridge P (Eds.) Applied Mycology, pp. 258-267. CAB International, Oxfordshire, UK.

Sheng Z and Liu Y 2011. Effects of silver nanoparticles on wastewater biofilms. Water Res. 45(18): 60396050 .

Sosa IO, Noguez C and Barrera RG 2003. Optical properties of metal nanoparticles with arbitrary shapes. J. Phys. Chem. B. 107(26): 6269-6275.

Vahabi K, Mansoori GA and Karimi S 2011. Biosynthesis of silver nanoparticles by fungus Trichoderma reesei (a route for large-scale production of AgNPs). Insciences J. 1(1): 65-9.

Wiley BJ, Im SH, Li ZY, McLella J, Siekkinen A and Xia Y 2006. Maneuvering the surface plasmon resonance of silver nanostructures through shape-controlled synthesis. J. Phys. Chem. B. 110: 1566615675.

(Manuscript received on 24 March, 2019; revised on 14 November, 2019) 